\title{
A systematic review and meta-analysis of community and primary-care-based hepatitis $C$ testing and treatment services that employ direct acting antiviral drug treatments
}

\author{
Andrew Radley ${ }^{1,2^{*}}$ (D) Emma Robinson ${ }^{2}$, Esther J. Aspinall ${ }^{3}$, Kathryn Angus ${ }^{4}$, Lex $\operatorname{Tan}^{2}$ and John F. Dillon ${ }^{2}$
}

\begin{abstract}
Background: Direct Acting Antiviral (DAAs) drugs have a much lower burden of treatment and monitoring requirements than regimens containing interferon and ribavirin, and a much higher efficacy in treating hepatitis $C$ $(\mathrm{HCV})$. These characteristics mean that initiating treatment and obtaining a virological cure (Sustained Viral response, SVR) on completion of treatment, in non-specialist environments should be feasible. We investigated the English-language literature evaluating community and primary care-based pathways using DAAs to treat HCV infection.

Methods: Databases (Cinahl; Embase; Medline; PsycINFO; PubMed) were searched for studies of treatment with DAAs in non-specialist settings to achieve SVR. Relevant studies were identified including those containing a comparison between a community and specialist services where available. A narrative synthesis and linked metaanalysis were performed on suitable studies with a strength of evidence assessment (GRADE).

Results: Seventeen studies fulfilled the inclusion criteria: five from Australia; two from Canada; two from UK and eight from USA. Seven studies demonstrated use of DAAs in primary care environments; four studies evaluated integrated systems linking specialists with primary care providers; three studies evaluated services in locations providing care to people who inject drugs; two studies evaluated delivery in pharmacies; and one evaluated delivery through telemedicine. Sixteen studies recorded treatment uptake. Patient numbers varied from around 60 participants with pathway studies to several thousand in two large database studies. Most studies recruited less than 500 patients. Five studies reported reduced SVR rates from an intention-to-treat analysis perspective because of loss to follow-up before the final confirmatory SVR test. GRADE assessments were made for uptake of HCV treatment (medium); completion of HCV treatment (low) and achievement of SVR at 12 weeks (medium).

Conclusion: Services sited in community settings are feasible and can deliver increased uptake of treatment. Such clinics are able to demonstrate similar SVR rates to published studies and real-world clinics in secondary care. Stronger study designs are needed to confirm the precision of effect size seen in current studies. Prospero: CRD42017069873.
\end{abstract}

Keywords: Hepatitis C, Systematic review, Direct acting antiviral drugs, Primary care

\footnotetext{
* Correspondence: aradley@dundee.ac.uk

${ }^{1} \mathrm{NHS}$ Tayside, Directorate of Public Health, Kings Cross Hospital, Clepington

Road, Dundee DD3 8EA, UK

${ }^{2}$ University of Dundee, Division of Cardiovascular Medicines and Diabetes

Ninewells Hospital and Medical School, Dundee DD1 9SY, UK

Full list of author information is available at the end of the article
}

(c) The Author(s). 2019 Open Access This article is distributed under the terms of the Creative Commons Attribution 4.0 International License (http://creativecommons.org/licenses/by/4.0/), which permits unrestricted use, distribution, and reproduction in any medium, provided you give appropriate credit to the original author(s) and the source, provide a link to the Creative Commons license, and indicate if changes were made. The Creative Commons Public Domain Dedication waiver (http://creativecommons.org/publicdomain/zero/1.0/) applies to the data made available in this article, unless otherwise stated. 


\section{Background}

Of the 71 million persons infected with HCV, 5.6 million (8\%) currently inject drugs [1, 2]. The World Health Organization (WHO) has defined global targets for HCV diagnosis and treatment, which represents a major step towards the aim of global elimination by 2030 [3].

However, rates of uptake of HCV testing, linkage to care and treatment remain low across many countries [4]. Barriers to accessing funded Direct Acting Antiviral (DAA) drug treatment may be due to provider concerns regarding co-morbidities, adherence, and side effects management [5]. Social factors affecting treatment access have been categorised as social stigma, housing, criminalisation, health care providers' attitudes and stigmatising practices, and gender [6]. Individuals may prioritise other needs and may be wary of the consequences of a diagnosis on their circumstances; health systems may present complex and rigid arrangements that must be navigated in order to access care [7]. The stigma associated with both injecting drug use and HCV infection is pervasive [8]. The concept of the care cascade has focussed attention on the performance of different pathways and the attrition of patients accessing testing, diagnosis, treatment and care [9].

It is common in many developed and developing countries, for specialist clinicians to provide HCV treatment, often from hospital outpatient facilities [10]. Recently, prescribing of DAAs has become common practice in many countries [10]. Treatment of HCV with these medicines is simple and well-tolerated [11]. The safety profile and high efficacy of DAAs means that HCV treatment can be delivered by a range of non-specialist clinicians including nurses, pharmacists and general practitioners, therefore providing enhanced access to virological cure (SVR) [12]. The ease of transferring care to community and primary care environments is assisted by the use of treatment regimens that do not contain ribavirin or interferon [13]. Progress with implementing treatment pathways provided by non-specialists in community and primary care environments has been identified as one of the key steps in the elimination of HCV [14]. The World Health Organization's Guidelines for the care and treatment of persons diagnosed with chronic hepatitis $\mathrm{C}$ virus infection promote simplified service delivery models: integration with other services; decentralised services supported by tasksharing; and community engagement, with the intention of reducing stigma and increase uptake of treatment [14].

This review was undertaken to identify rates of treatment uptake, treatment completion and achievement of sustained viral response for adults infected with hepatitis $\mathrm{C}$ using DAA-only treatment regimens in community and primary care-based care pathways, evaluated by studies using observational and experimental study designs. Studies that compared community-based treatment care pathways with specialist care were actively sought.

\section{Methods}

This systematic review was undertaken and reported according to the Preferred Reporting Items for Systematic Reviews and Meta-Analyses (PRISMA) statement [15]. The methods of analysis and defined inclusion criteria were specified in advance and documented in a study protocol. The study was registered in PROSPERO (CRD42017069873). The PICOS elements defined for this review are set out in Table 1.

The rationale adopted in the design of the PICOS elements was intended to provide some answers to the questions raised by the WHO Guidance and its recommendations for simplified and decentralised treatment delivery models, integrated with other services in community and primary-care environments [14]. Therefore a population over 18 years old was selected, as being less likely to have gained their infection through vertical transmission. Co-infected individuals with other blood borne virus infections were also excluded as their care was likely to be more complex, requiring specialist rather than simplified care. Studies from prison populations were excluded since these individuals lived in contained communities. Studies that utilised interferon and ribavirin-based treatment regimes as the primary intervention were also excluded, since monitoring and patient management requirements, made simplified and decentralised care less likely. Sustained viral response at

Table 1 Elements of the PICOS question defined for this review

\begin{tabular}{|c|c|c|}
\hline & Inclusion & Exclusion \\
\hline Population & $\begin{array}{l}\text { Age } 18 \text { years and over } \\
\text { Infected with hepatitis } C\end{array}$ & $\begin{array}{l}\text { Age less than } 18 \text { years } \\
\text { Co-infection with Hepatitis B virus } \\
\text { Co-infection with HIV }\end{array}$ \\
\hline Intervention & $\begin{array}{l}\text { Provision of hepatitis C treatment in any primary care and community environments } \\
\text { Treatment using any direct acting antiviral therapy } \\
\text { Care provider could be any health care provider }\end{array}$ & $\begin{array}{l}\text { Hepatitis } C \text { treatment in prison populations } \\
\text { Treatment with ribavirin / interferon regimes } \\
\text { as the primary intervention }\end{array}$ \\
\hline Comparison & Care in any hospital or secondary care environment or no comparison group & \\
\hline Outcome & Treatment uptake, treatment completion and SVR outcomes & \\
\hline $\begin{array}{l}\text { Study } \\
\text { design }\end{array}$ & $\begin{array}{l}\text { Observational studies, retrospective or prospective cohort studies, randomised trials; } \\
\text { conference abstracts; qualitative and mixed methods studies }\end{array}$ & Case studies; systematic reviews \\
\hline
\end{tabular}


12 weeks (SVR12) was taken as a marker for virological cure; failure to achieve SVR may be attributed to both treatment failure and loss to follow-up [16]. Studies were restricted to the English language since study resources precluded any translation activities. Published studies were utilised including conference abstracts, in order to capture results from early studies when the first DAAs were introduced into practice.

\section{Search strategy}

Published research was identified by formal searches of five electronic databases (Cinahl, Embase, Medline, PsycINFO, PubMed) from January 2013 to December 2017, as well as Google Scholar. The last search was run on 11 December 2017. Search topics included "hepatitis C", "treatment" and "setting". A comprehensive list of search terms related to each of the search topics was used to develop a search strategy for each electronic database. Search strings were formulated by using a combination of keywords and indexed subject headings (MeSH and EMTREE terms). Primary care was defined using the WHO accepted terminology that promotes Primary Care as a key process in the health system: "it is first-contact, accessible, continued, comprehensive and coordinated care" [17] and community environments being the geographical locations where groups of people live.

The full search strategy is set out in Additional file 1. Reference lists of selected articles, citing articles and relevant review articles retrieved during the initial search were handsearched and forward citation checks were undertaken to identify any additional studies. Abstracts from the selected scientific conferences were screened for review eligibility.

\section{Study selection}

Data retrieved through the study search strategy were imported into EndNote X8 (Thomson Reuters, New York, NY, USA) and any duplicates removed. Titles obtained from the initial search strategy were screened and irrelevant citations were removed. Abstracts were then assessed using the inclusion and exclusion criteria by two reviewers independently (AR and LT) to establish a relevant pool of evidence for further evaluation. Full-texts from all abstracts identified for further evaluation and were double-screened independently by the two reviewers to assess whether they met the defined inclusion and exclusion criteria. In the event of a disagreement, the senior investigator (JFD) determined final inclusion. The lead author contacted conference abstract authors to attempt to obtain further study results if available. Studies published from identified conference abstracts were screened for review.

\section{Data collection process and data items collected}

Data from studies included for analysis were extracted by the lead author (AR) using a standardised data extraction form (Microsoft Excel 2010 Redmond, WA, USA). A second reviewer (ER) also independently assessed the extracted data, and disagreements were resolved by discussion until consensus was reached. The following variables were documented: first author, title, publication year, study design, study location, setting, intervention description, comparator description, sample size outcome description and number of participants achieving SVR12 (and percentage if applicable).

\section{Risk of bias assessment in individual studies}

The risk of bias in individual studies was assessed by two reviewers (AR and ER) using the Cochrane Collaboration's risk of bias tool for randomised studies [18] and the "NewcastleOttawa Scale (NOS) for assessing the quality of nonrandomised studies in meta-analyses" [19]. For randomised studies, these outcomes were evaluated along the six domains: selection bias, performance bias, detection bias, attrition bias, reporting bias, and other bias. The domains deemed as 'high risk' of bias for each study per outcome were determined. Outcomes for the non-randomised studies were evaluated along seven domains: bias due to confounding; bias in selection of participants into study; bias in classification of interventions; bias due to deviations from intended interventions; bias due to missing data; bias in measurement of outcomes; and bias in selection of the reported result. The overall risk of bias for these studies was classified into five categories: low risk of bias; moderate risk of bias; serious risk of bias; critical risk of bias or no information.

The NOS scale measures three items: selection of cases and controls including their definition and representativeness; comparability of cases and controls in design and analysis; and exposure ascertainment. The scale has a minimum score of 0 and a maximum score of 9 . Risk of bias was rated as high, medium or low according to the scores obtained by reviewing the selection, comparator and exposure categories. Risk of bias was rated low if studies scored 8 or 9; medium risk if studies were scored as 6 or 7. Studies were rated as having a high risk of bias if they were scored as having 5 or less or scored zero for the comparator category [20].

We assessed the strength of evidence using GRADE [21]. The scheme evaluates a required group of domains (study limitations, directness, consistency, precision and reporting bias) and enables grading of the strength of evidence as High; Moderate; Low or Insufficient. Use of this approach enabled us to summarise the outcomes and findings and make clear judgements about the effects of the interventions.

\section{Data analysis}

The characteristics and findings of the studies included were summarised and structured using tables. Studies evaluating similar service environments in community 
and primary care-settings were grouped together to facilitate comparison.

Study designs, participants, interventions and reported outcomes varied significantly, and a meta-analysis was unable to be performed on all included studies. Studies were excluded from the meta-analysis if the reviewers considered them to be sufficiently flawed so as not to contribute meaningfully to the body of evidence [21].

The characteristics and findings of included studies amenable to meta-analysis were summarised using tables and forest plots. Risk ratio (RR) and corresponding 95\% confidence interval $(95 \% \mathrm{CI})$ was calculated for each study outcome, using the initial number of eligible participants included and the number achieving the outcome of interest in each arm. Analyses were conducted using statistical package Stata v14.0 (College Station, TX, USA).

\section{Data synthesis}

\section{Deriving pooled estimates of treatment uptake, treatment} completion and SVR

Treatment uptake, treatment completion and SVR and their exact $95 \%$ confidence intervals (CIs) were calculated assuming a binomial distribution. Pooled estimates were derived using random- or fixed-effects methods, according to whether significant heterogeneity (defined as $\mathrm{I}^{2}>30 \%$ ) was or was not present, respectively. Sensitivity analysis was used to assess the impact of study quality (restricting to studies with an NOS score $\geq 6$ ) on the pooled estimate of SVR.

Further sensitivity analysis was used to assess the impact of conference abstracts on the pooled estimate of SVR. We identified studies using similar environments from which to deliver care and grouped them into categories. Factors identified as linking studies within categories were examined as well as factors that differentiated studies from each other.

\section{Results}

\section{Study selection}

The searches yielded 9137 publications after removal of duplicates (Fig. 1). This resulted in 121 articles retrieved for full text inspection and 17 included for analysis. Explanations for exclusion of studies at the full text stage are provided in Fig. 1. These included: did not fulfil inclusion criteria; no treatment intervention; review or opinion article; other (e.g. insufficient detail reported in conference abstract).

\section{Study characteristics}

Studies evaluated care pathways in primary care [22-28]; in integrated health systems (Extension for Community Healthcare Outcomes, ECHO) [29-32]; in opioid treatment centres [33-35]; in pharmacies/pharmacist clinics $[36,37]$ and by telemedicine [38]. Characteristics and findings of included studies are set out in Table 2. These studies originated from United States of America (8); Australia (5); United Kingdom (2); and Canada (2). The number of identified studies published as conference abstracts reflected the length of time that DAAs have been widely available outside specialist environments. Six from seventeen studies were only available as conference abstracts. There were two randomised controlled trials, four cohort studies, nine retrospective data analyses and two prospective non-experimental designs. All were conducted on populations at high risk of $\mathrm{HCV}$ infection, such as people who inject drugs and people on Opioid Substitution Therapy (OST) programmes. Table 3 describes the outcomes from the meta-analysis of selected studies and Table 4 defines the Strength of Evidence Assessment for identified studies answering the PRISMA objective. Details of assessment of bias and design for studies are located in Additional file 2 (non-randomised) and Additional file 3 (randomised)).

\section{Primary care}

Seven studies evaluated interventions to enhance treatment uptake and achievement of SVR in primary care environments [22-28]. One study was a randomised controlled trial (RCT), two were cohort studies and four were non-randomised studies. Four studies utilised nurses in delivery of the care pathway. Three studies included uptake of testing and assessment in their description of care and all the studies discussed uptake of treatment and ascertainment of SVR. The RCT reported a significant difference between those commencing treatment in primary care arm than in the Standard of Care arm (SOC) $(75 \%$ Vs $34 \%, p<0.001)$ and proportion gaining an SVR12 was significantly higher in the primary care arm than in the SOC arm ( $49 \%$ vs $34 \%, p=0.043)$.

Two studies reported a reduction in potential SVR rates because of failure of participants to complete the confirmatory blood test at 12 weeks after completion of DAA treatment. All studies reported increased access to treatment in primary care environments and high rates of SVR attainment.

\section{Integrated health systems (ECHO)}

Four studies provided evaluations of care through integration of specialist centres with primary care delivery [29-32]. One study was a retrospective cohort study and three were non-randomised studies. Three of the four studies utilised the "ECHO" care pathway in which hepatitis specialists support primary care providers through video-conferencing and collaboration on specific cases, with a defined curriculum and active mentorship [39]. None of the studies discussed uptake of testing amongst their treated cohorts. All studies increased access to treatment and high rates of attainment of SVR. 


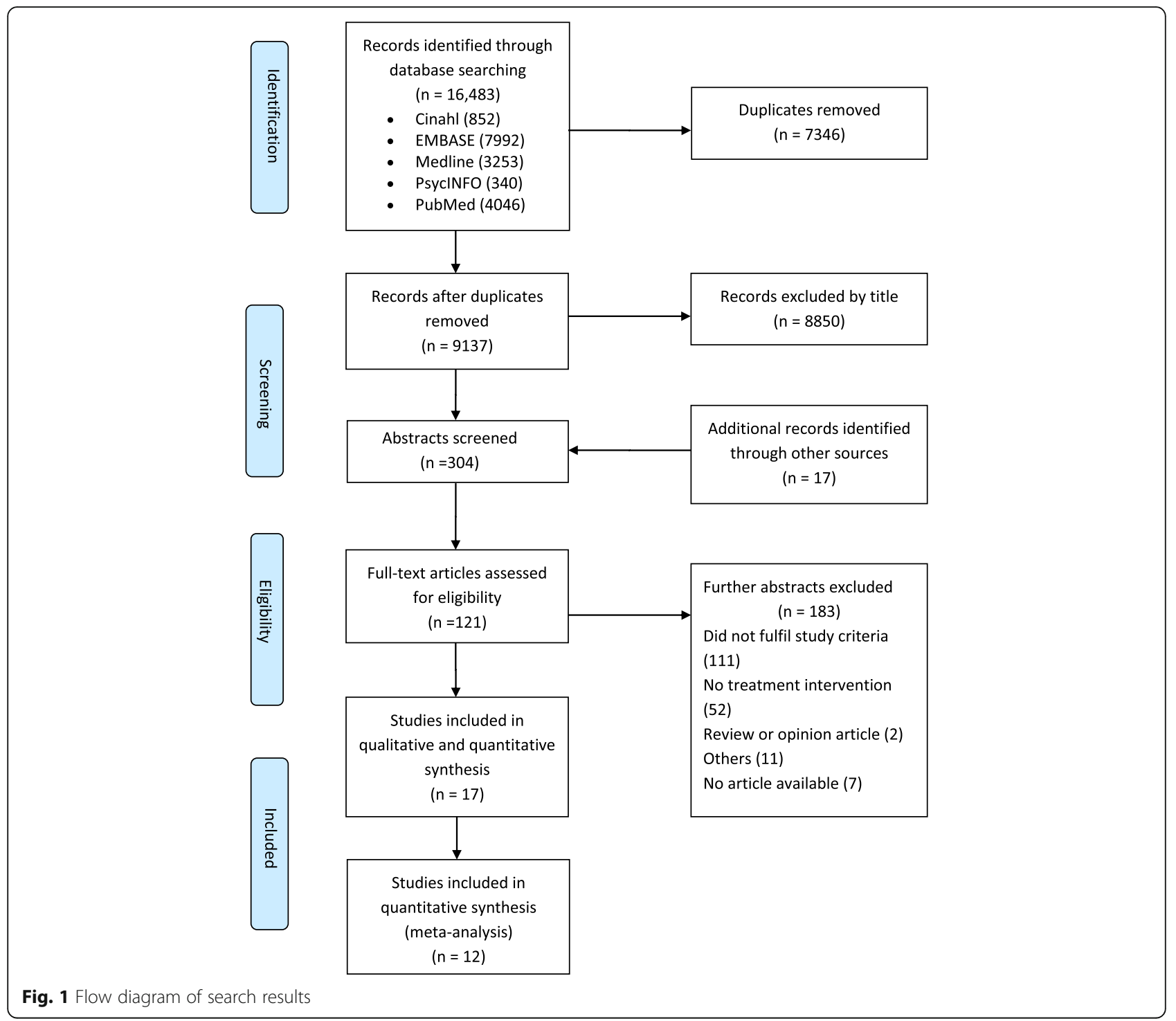

\section{Opioid treatment Centres}

Three studies evaluated care provision in dedicated setting where people with opioid addiction received harm reduction and treatment services [33-35]. All three studies were non-randomised analyses of treatment data and assessed the uptake and completion of treatment by participants using these services. No assessment of the extent of testing of these populations was discussed. All studies reported high rates of treatment uptake and treatment completion in diagnosed individuals. These studies all described problems with retention of participants in the service post-treatment with consequent reductions in uptake of confirmatory SVR testing.

\section{Pharmacies / pharmacist clinics}

Two studies evaluated hepatitis $\mathrm{C}$ care provision by pharmacists in community and primary care settings $[36,37]$.
One study was a feasibility RCT that compared the delivery of a community pharmacy test and treatment pathway with standard hospital-based care. One study was a nonrandomised data analysis. The RCT demonstrated an increase in testing uptake, when the participant received all care in a pharmacy environment and showed increased retention in care. Data from this study also demonstrates a marked loss of patients from the care pathway when they were asked to attend the local hospital. The non-randomised study concluded that patients treated in pharmacist clinics achieve high rates of SVR similar to non-pharmacist clinics.

\section{Telemedicine}

A single cohort database study [38] compared treatment uptake and SVR rates in participants cared for through a telemedicine pathway $(n=157)$ with participants cared for through a standard care pathway $(n=1130)$. The study 


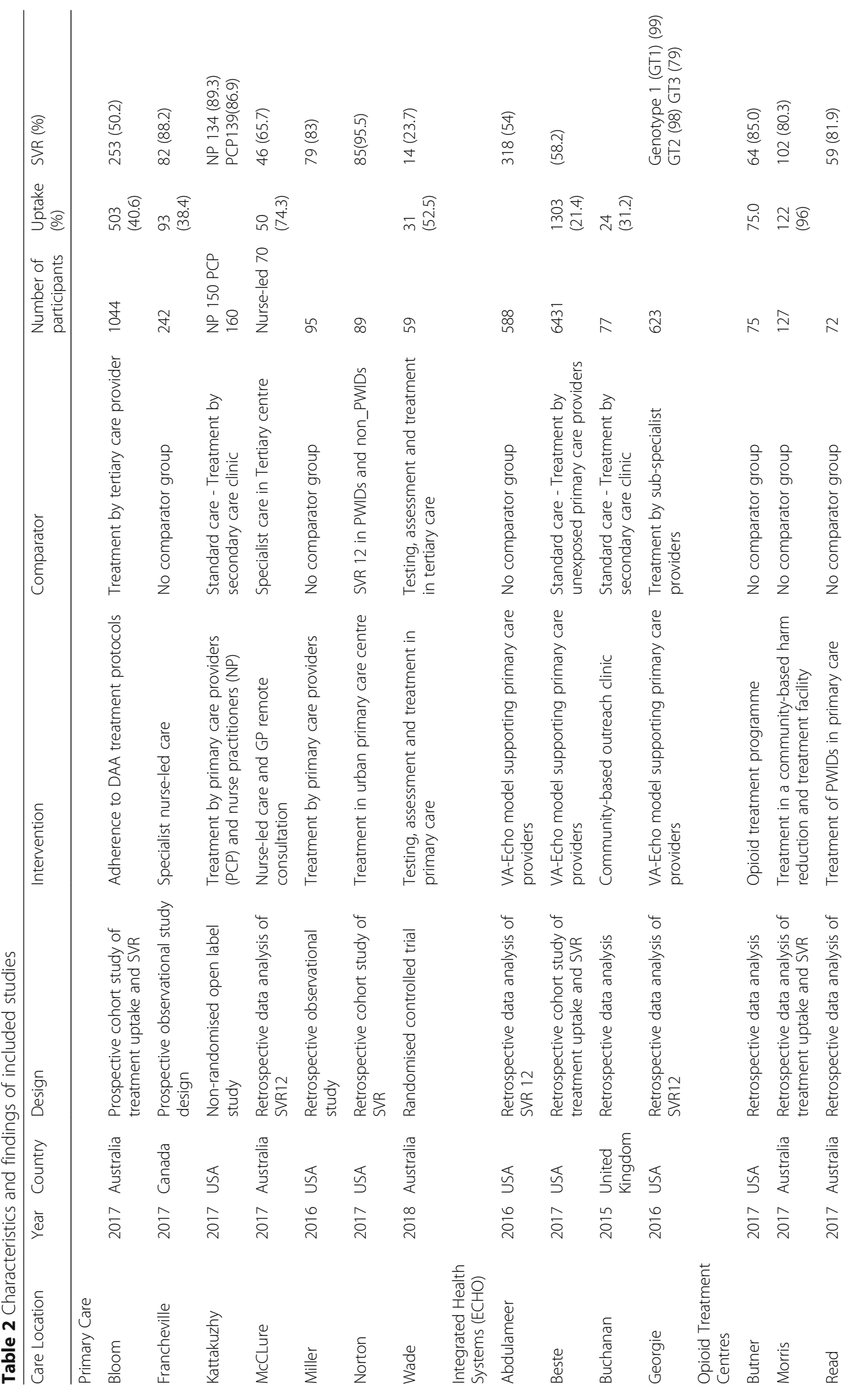




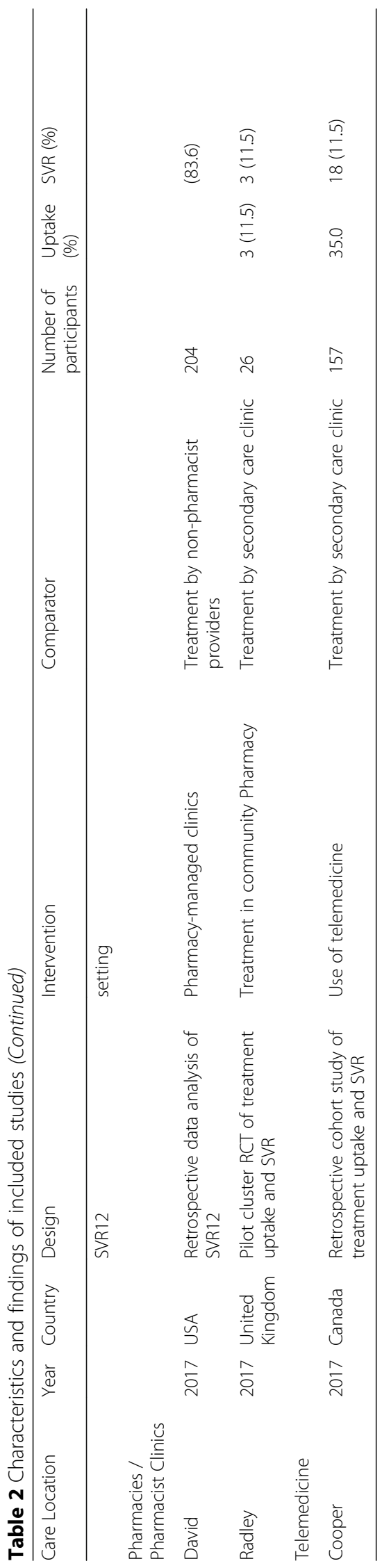


Table 3 Meta-analysis of studies examining treatment uptake, treatment completion and SVR among people with Hepatitis C treated in a variety of community settings or specialist hospital care

\begin{tabular}{|c|c|c|c|c|c|c|c|c|c|}
\hline \multirow[t]{2}{*}{ Inclusion Criteria } & \multicolumn{3}{|c|}{ Treatment Uptake } & \multicolumn{3}{|c|}{ Treatment Completion } & \multicolumn{3}{|l|}{ SVR } \\
\hline & $\begin{array}{l}\text { No. Of } \\
\text { studies }\end{array}$ & $\begin{array}{l}\text { Heterogeneity } \\
\left(I^{2}\right)\end{array}$ & $\begin{array}{l}\text { Pooled estimate } \\
(95 \% \mathrm{Cl})\end{array}$ & $\begin{array}{l}\text { No. Of } \\
\text { studies }\end{array}$ & $\begin{array}{l}\text { Heterogeneity } \\
\left(1^{2}\right)\end{array}$ & $\begin{array}{l}\text { Pooled estimate } \\
(95 \% \mathrm{Cl})\end{array}$ & $\begin{array}{l}\text { No. Of } \\
\text { studies }\end{array}$ & $\begin{array}{l}\text { Heterogeneity } \\
\left(I^{2}\right)\end{array}$ & $\begin{array}{l}\text { Pooled estimate } \\
(95 \% \mathrm{Cl})\end{array}$ \\
\hline $\begin{array}{l}\text { Opioid Treatment } \\
\text { Centres }\end{array}$ & & & & 2 & $77.7 \%$ & $91.9(82.2-100)$ & 3 & $0.0 \%$ & $82.3(77.8-86.8)$ \\
\hline $\begin{array}{l}\text { Integrated Health } \\
\text { System (ECHO) }\end{array}$ & 1 & $\begin{array}{l}\text { Not } \\
\text { applicable }\end{array}$ & $75.6(68.0-83.2)$ & 1 & $\begin{array}{l}\text { Not } \\
\text { applicable }\end{array}$ & $96.8(93.2-100)$ & 2 & $84.6 \%$ & $81.3(66.9-95.5)$ \\
\hline Telemedicine & 1 & $\begin{array}{l}\text { Not } \\
\text { applicable }\end{array}$ & $22.3(15.8-28.8)$ & & & & 1 & $\begin{array}{l}\text { Not } \\
\text { applicable }\end{array}$ & $51.4(34.8-68.0)$ \\
\hline Primary Care & 1 & $\begin{array}{l}\text { Not } \\
\text { applicable }\end{array}$ & $67.4(53.9-80.9)$ & 1 & $\begin{array}{l}\text { Not } \\
\text { applicable }\end{array}$ & $100(97.95-100)$ & 5 & $94.9 \%$ & $74.4(60.3-88.5)$ \\
\hline $\begin{array}{l}\text { Pharmacies / } \\
\text { Pharmacist Clinics }\end{array}$ & 1 & $\begin{array}{l}\text { Not } \\
\text { applicable }\end{array}$ & $66.67(58.3-75.1)$ & & & & 2 & $89.0 \%$ & $79.0(79.2-98.9)$ \\
\hline Specialist Care & 2 & $0.0 \%$ & $34.5(31.79-37.29)$ & & & & 5 & $96.8 \%$ & $73.46(60.9-85.9)$ \\
\hline
\end{tabular}

Abbreviations: $\mathrm{Cl}$, Confidence interval; SVR, Sustained virologic response

a. Random-effects method used if $\mathrm{I}^{2} \geq 30 \%$

demonstrated increased access to care form under-served and remote areas and concluded that the telemedicine intervention achieved high rates of treatment initiation and SVR.

\section{Data synthesis}

The 12 studies eligible for meta-analysis examined treatment uptake, completion and SVR in a variety of primary care environments; integrated systems (ECHO) that linked specialists with primary care providers; opioid treatment centres; pharmacies / pharmacist clinics; telemedicine and specialist hospital care. The remaining five studies were unsuitable for meta-analysis due to non-reporting of the required outcomes, use of Pegylated interferon or insufficient time to achieve SVR. Across the 12 studies, the pooled estimate is shown in Additional file 4 Table S3. Forest plots for suitable studies are set out in Figs. 2, Fig. 3 and Fig. 4. These plots demonstrate that across the variety of community and primary care environments, a consistent direction of effect to improve treatment uptake, treatment completion and achievement of SVR is seen. Greater uptake was seen for the Primary Care and Pharmacy Locations, compared to the Specialist Care Location and comparable SVR rates were demonstrated (Table 2).

In this analysis, heterogeneity was noted to be high so a sensitivity analysis restricting to higher-quality studies (NOS score $\geq 6$ ) was performed. Despite this the heterogeneity remained high. A further sensitivity analysis was performed restricting the meta-analysis to published studies only. See Additional file 3 in the appendix. This had no impact on heterogeneity.

\section{Discussion}

This paper reviews evaluations of care pathways that utilise DAAs in a range of community and primary care settings. The WHO Guidelines on care and treatment of persons diagnosed with chronic $\mathrm{HCV}$ infection promote simplified service delivery models; integration with other services; decentralised services supported by task-sharing; and community engagement to address stigma and increase reach [14]. The studies considered in this systematic review

Table 4 Summary of key findings, outcomes and strength of evidence

\begin{tabular}{|c|c|c|c|}
\hline Outcome & $\begin{array}{l}\text { Study designs/ } \\
\text { No. Studies }\end{array}$ & Findings and Direction of Effect & GRAD E[21] \\
\hline 1. Uptake of HCV treatment & $\begin{array}{l}\text { RCT }-2 \\
\text { Cohort }-3 \\
\text { Observational }-5\end{array}$ & $\begin{array}{l}\text { Two RCTs assessed as having low risk of bias } \\
\text { reported a positive effect on uptake with precision } \\
\text { and a consistent positive direction of effect. One } \\
\text { cohort study assessed as having medium-grade } \\
\text { study limitations also reported a positive } \\
\text { effect on uptake. }\end{array}$ & Medium \\
\hline 2. Completion of Treatment & $\begin{array}{l}\text { Cohort - } 1 \\
\text { Observational - } 2\end{array}$ & $\begin{array}{l}\text { One cohort study with medium study limitations } \\
\text { reported a positive direction of effect on uptake. }\end{array}$ & Low \\
\hline 3. Sustained Viral Response at 12 weeks (\%)(SVR12) & $\begin{array}{l}\mathrm{RCT}-2 \\
\text { Cohort - } 4 \\
\text { Observational - } 11\end{array}$ & $\begin{array}{l}\text { Two RCTs assessed as having low risk of bias } \\
\text { reported a positive effect on SVR but were imprecise } \\
\text { in the estimate of effect size. Four cohort studies and } \\
11 \text { observational studies with over 10,000 participants } \\
\text { all reported a consistent positive direction of effect, } \\
\text { but with significant study limitations. }\end{array}$ & Medium \\
\hline
\end{tabular}




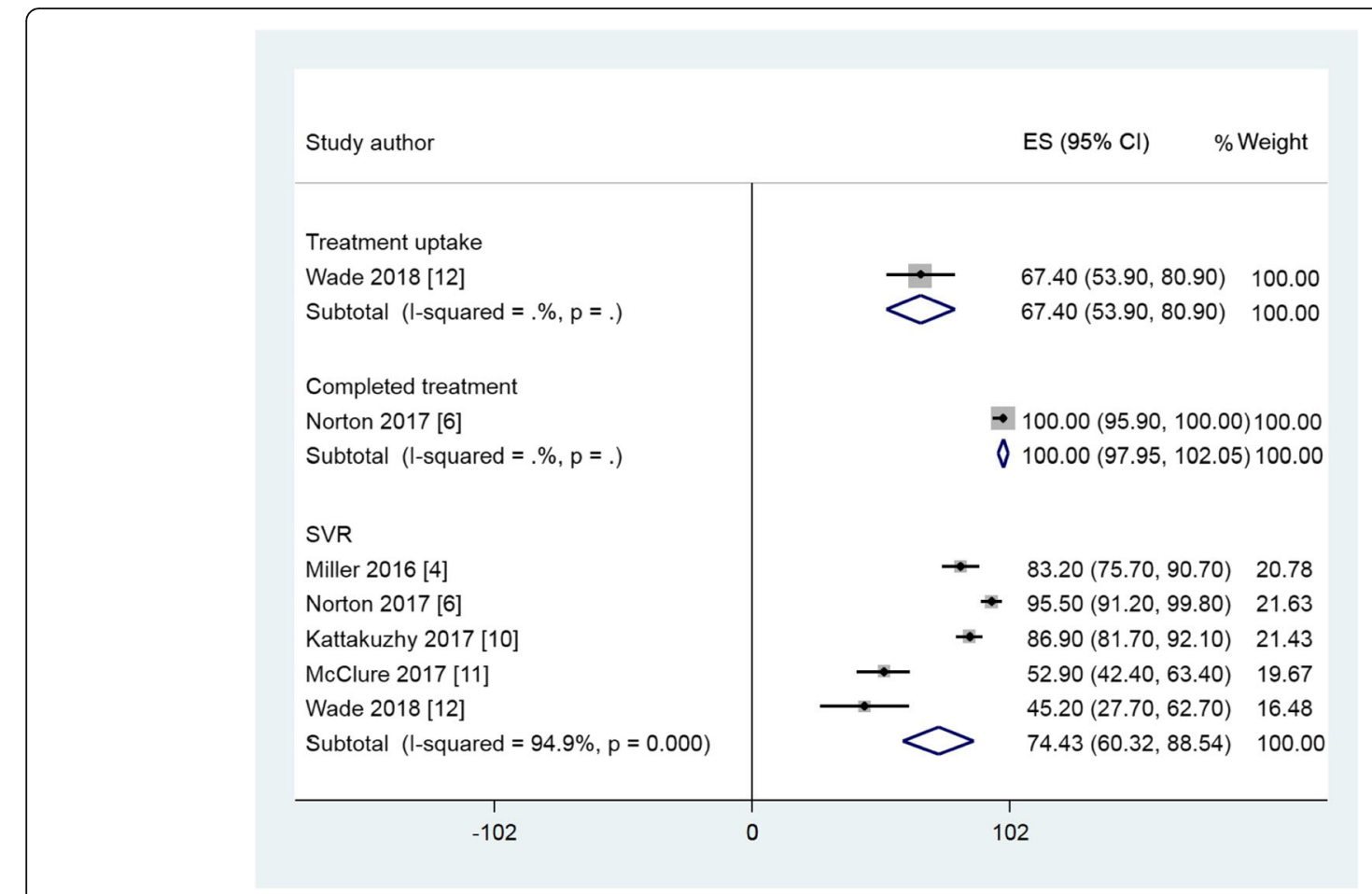

Fig. 2 Forest plots of treatment uptake, completed treatment and SVR rates for selected studies in the Primary Care Location

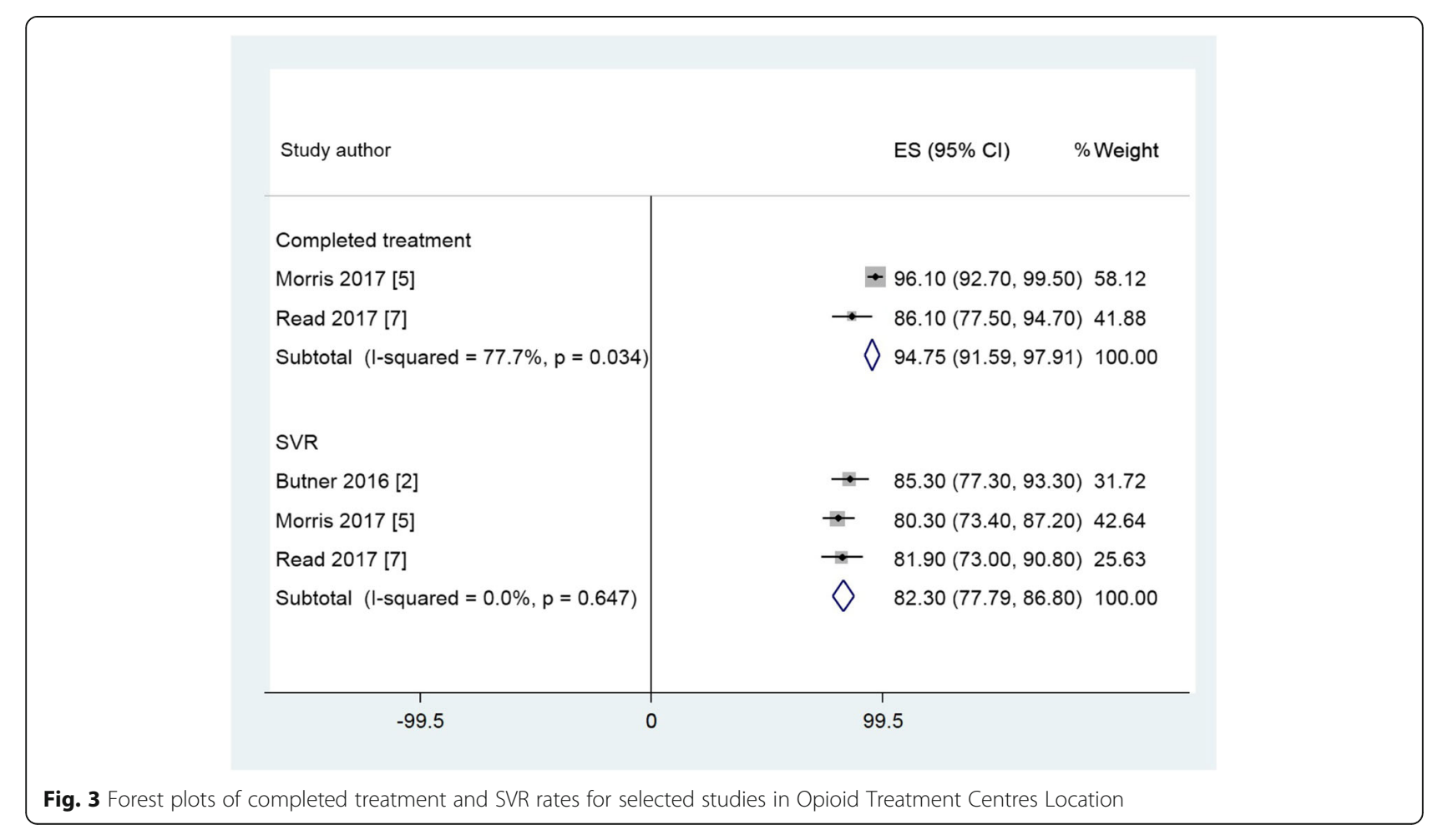




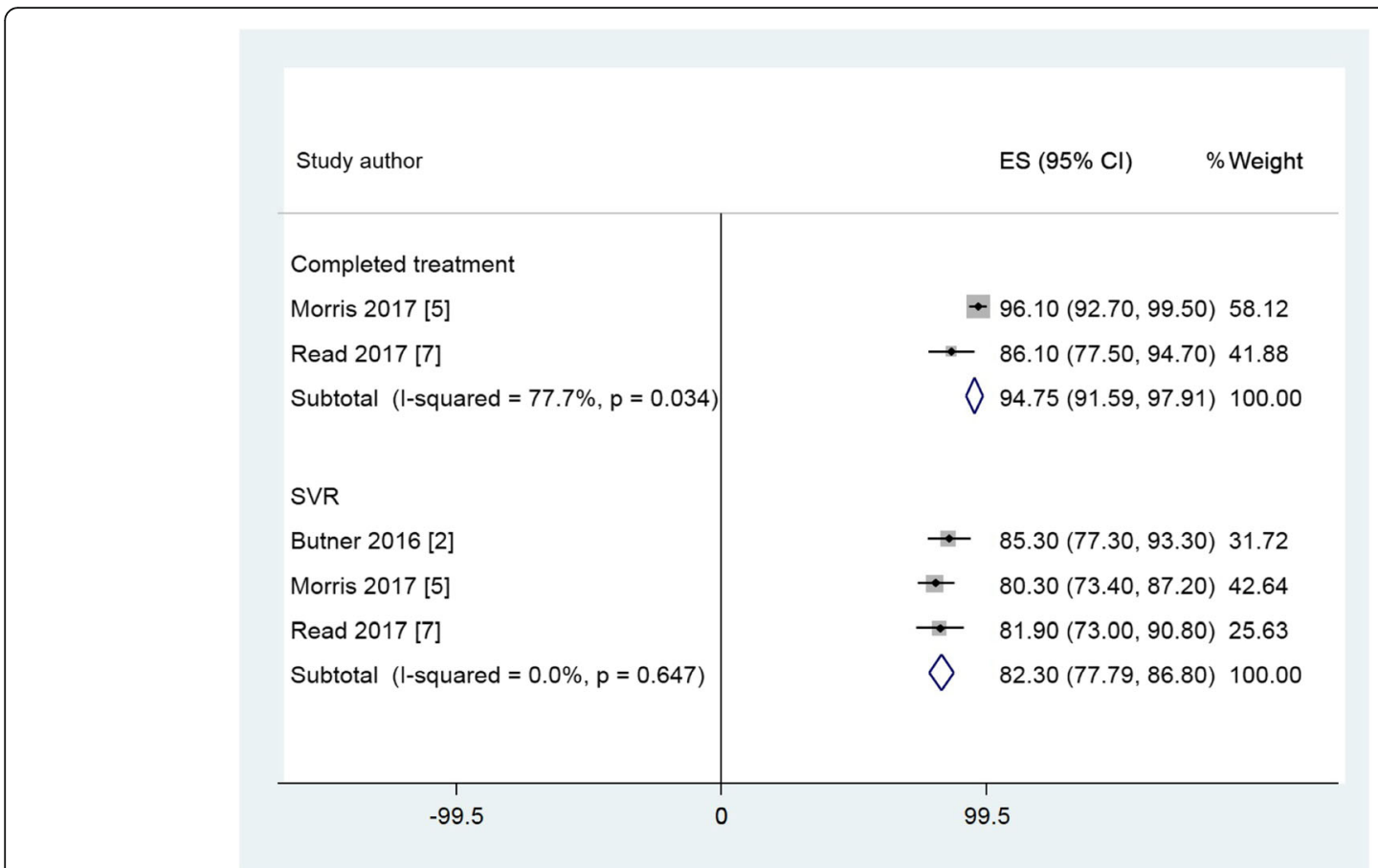

Fig. 4 Forest plots of treatment uptake and SVR rates for studies in the Pharmacy / Pharmacist Clinic Location

and meta-analysis therefore provide some evidence for the extent of implementation of these guidelines.

The studies identified that met our inclusion criteria were grouped according to location: primary care; integrated health care systems (ECHO); opioid treatment centres; in pharmacies / pharmacist clinics; and through telemedicine. These care pathways acknowledged the need to provide local services with reach into the communities where people with hepatitis $\mathrm{C}$ live their lives.

In all three areas assessed in our study: uptake of treatment; completion of treatment; and attainment of SVR, a positive outcome was reported by all identified studies. This was seen across each of the distinct environments from which the care was provided. Since the positive outcomes were drawn from distinctly different pathways of care, further confidence might be inferred from this consistency of direction of effect. However, amongst the studies that met our inclusion criteria, there was a lack of studies using comparators from specialist centres. Data contained in these studies nevertheless demonstrated high uptake of treatment and high rates of attainment of SVR: among populations of vulnerable people who normally struggle to access care. Studies that did include comparators showed no significant differences in uptake or SVR. Several of the studies reported an increased uptake of treatment, but most reported equivalence. Some studies reported lower rates of attainment of SVR, because of study participants failing to undergo a confirmatory blood test post-treatment, within the study timelines. With DAAs SVR rates of greater than 97\% are delivered if patients adhere to treatment, therefore completion of therapy can be a surrogate for SVR [16].

Previous systematic reviews have considered barriers and facilitators to care, as well as the views and experiences of people who inject drugs [7, 40]. These studies concluded that the target groups for $\mathrm{HCV}$ often had poor levels of knowledge about the infection and of the processes involved with testing and treatment. A fear of stigma and discrimination and a reticence to discuss risk behaviours tended to prevent engagement. These barriers could be addressed through educating participants, increasing awareness and redress of institutionalised stigma and integrating $\mathrm{HCV}$ treatment pathways into other services where the target group were likely to go.

Increased uptake of testing has been observed when testing is offered at the same time as other routine care [4]; with integrated services for both opioid users and with mental health services. There are advantages to targeting services at populations with predicted high prevalence of HCV [41]. Provision of HCV treatment as part of a directly observed treatment arrangement, increased attainment of SVR [42]. Achievement of these factors within local health systems needs to be commonplace if the WHO target for elimination is to be met [43]. There is some evidence that this is now happening [44].

The results from this systematic review highlight the lack of well-controlled randomised controlled trials and 
comparative studies, with just two randomised controlled trials identified and four cohort studies. While the publication of such studies is an important step in building confidence that decentralisation of hepatitis $\mathrm{C}$ treatment can be accomplished, the paucity of evidence reflects the difficulty in funding pathways to care studies and the relatively recent removal of the restrictions on the use of DAAs. Two further studies have been commenced identify that further evaluations of interferonfree treatments in primary care environments are underway $[45,46]$.

As with most systematic reviews, the quality of the studies and the heterogeneity of the study populations included in the analysis present a limitation of this study. The sensitivity analyses performed for our analysis did not have an impact on heterogeneity, meaning that an unexplained source of heterogeneity may be present. These difficulties may reflect the variety of ways in which patients can access HCV treatment. This may be positive and may be explained by the development of more patient centred pathways. These factors prevented a meta-analysis being achieved for many of the studies identified as eligible through the PICOS question defined for this review. Many of the studies that met the inclusion criteria were only available as conference abstracts at the time of review, including one of the randomised controlled trials. Nevertheless, over 10,000 participants were included in the identified studies. All studies had a consistent direction of effect, providing optimism that future evaluations will confirm with precision the effect size that should be delivered by simplifying treatment pathways and decentralising them to primary care. In terms of further limitations, we acknowledge limitations in the chosen methods for the systematic review, including potential publication bias to the findings by excluding non-English language studies; or any other biases introduced by our chosen inclusion and exclusion criteria.

\section{Conclusion}

This systematic review and meta-analysis identified studies which demonstrate the feasibility of decentralising care and providing local services with reach into communities of people infected with HCV. Such pathways may increase uptake of treatment and can provide sustained viral responses equivalent to those attained in specialist centres. Further studies are needed to confirm the promising start to the implementation of interferonfree treatment regimens. The successful implementation of such pathways to deliver successful patient outcomes is a key requirement for a "treatment as prevention" strategy as a pathway to elimination of HCV [47].

\section{Supplementary information}

Supplementary information accompanies this paper at https://doi.org/10. 1186/s12913-019-4635-7.

Additional file 1. Sample search strategy for MEDLINE(R) Epub Ahead of Print, In-Process \& Other Non-Indexed Citations, Ovid MEDLINE(R) Daily and Ovid MEDLINE(R) 1946 to Present

Additional file 2. Table S1 Assessment of risk of bias for included studies - Newcastle/Ottawa Assessment non-randomised studies.

Additional file 3. Table S2 Cochrane Assessment of Randomised Studies.

Additional file 4. Table S3Meta-analysis of published studies examining sustained virologic response among people with Hepatitis C treated in a variety of community settings or specialist hospital care.

\section{Abbreviations}

DAA: Direct Acting Antiviral; GRADE: Grading of Recommendations Assessment, Development and Evaluation; HCV: Hepatitis C; HIV: Human Immunodeficiency Virus; NOS: Newcastle Ottawa Scale; OST: Opioid Substitution Therapy; PICOS: Population; Intervention; Comparison; Outcome; Study Design; PRISMA: Preferred Reporting Items for Systematic Reviews and Mata-Analysis; PWID: People Who Inject Drugs; RCT: Randomised Controlled Trial; RR: Risk Ratio; SOC: Standard of Care; SVR: Sustained Viral Response; SVR12: Sustained Viral response at 12 weeks; WHO: World Health

Organization

Acknowledgements

Not applicable

\section{Availability of data and material}

All data generated or analysed during this are included in this published article (and its supplementary information files).

\section{Authors contributions}

Study concept and design - AR, ER, EJA, KA, JFD.

Data acquisition - AR LT, ER, KA.

Interpretation of data - AR, LT, ER.EJA, KA, JFD.

Statistical analysis - ER, EJA.

Drafting of manuscript - AR, ER, EJA, LT, KA, JFD.

Critical review of contributions - AR, ER, EJA, KA, LT, JFD.

Final approval of manuscript - AR, ER, EJA, KA, LT, JFD.

All authors have read and approved the manuscript.

\section{Funding}

Not applicable.

Ethics approval and consent to participate Not applicable.

Consent for publication

Not applicable.

\section{Competing interests}

AR: Honorariums from Gilead and Abbvie; Research Grants from Abbvie, Gilead, Bristol Myers Squibb and Roche.

ER: No competing interests to declare.

EJA: no competing interests to declare.

$\mathrm{KA}$ : no competing interests to declare.

LT: no competing interests to declare.

JFD: Research Grants, and Honorariums from Abbvie, Bristol Myers Squibb, Gilead, Janssen, Merck Sharp \& Dohme and Roche.

\section{Author details}

${ }^{1} \mathrm{NHS}$ Tayside, Directorate of Public Health, Kings Cross Hospital, Clepington Road, Dundee DD3 8EA, UK. University of Dundee, Division of

Cardiovascular Medicines and Diabetes Ninewells Hospital and Medical

School, Dundee DD1 9SY, UK. ${ }^{3}$ School of Health and Life Sciences, Glasgow

Caledonian University Glasgow and Health Protection Scotland, NHS National 
Services, Scotland, UK. ${ }^{4}$ Institute for Social Marketing, Faculty of Health

Sciences and Sport University of Stirling, Stirling FK9 4LA, UK.

\section{Received: 20 December 2018 Accepted: 14 October 2019} Published online: 28 October 2019

\section{References}

1 The Polaris HCV Collaborators. Global prevalence and genotype distribution of hepatitis C virus infection in 2015: a modelling study. Lancet Gastroenterol Hepatol. 2017;2:161-76. https://doi.org/10.1016/S24681253(16)30181-9.

2 WHO. Global hepatitis report 2017. World Health Organization; Geneva 2017. https://www.who.int/hepatitis/publications/global-hepatitis-report2017/en/

3 WHO 2016. Combating hepatitis B and C to reach elimination by 2030 advocacy brief. World Health Organization, Geneva May 2016. http://www. who.int/hepatitis/publications/hep-elimination-by-2030-brief/en/

4 Bajis S, Dore GJ, Hajarizadeh B, Cunningham EB, Maher L, Grebely J. Interventions to enhance testing, linkage to care and treatment uptake for hepatitis $C$ virus infection among people who inject drugs: a systematic review. Int J Drug Policy. 2017:47:34-46. https://doi.org/10.1016/.drugpo.2017.07.002

5 World Health Organization Global Health Sector Strategy on Viral Hepatitis 2016-2021. Towards ending viral hepatitis. World Health Organization Geneva 2016 https://www.who.int/hepatitis/strategy2016-2021/ghss-hep/en/

6 Harris M, Rhodes. Hepatitis C treatment access and uptake for people who inject drugs: a review mapping the role of social factors Harm Reduction Journal 2013 10, 7. doi: https://doi.org/10.1186/1477-7517-10-7.

7 Jones L, Atkinson A, Bates G, McCoy E, Porcellato L, Beynon C. Views and experiences of hepatitis $C$ testing and diagnosis among people who inject drugs: systematic review of qualitative research. Int J Drug Policy. 2014;25: 204-11 10.10.1016/j.drugpo.2013.11.004.

8 Dowsett LE, Coward S, Lorenzetti DL, MacKean G, Clement F. Living with hepatitis $C$ virus: a systematic review and narrative synthesis of qualitative literature. Can J Gastroenterol Hepatol. 2017. https:/doi.org/10.1155/2017/ 3268650.

9 Simmons R, Ireland G, Irving W, Hickman M, Sabin C, ljaz S, Ramsay M, Lattimore $S$, Mandal $S$. Establishing the cascade of care for hepatitis $C$ in England - benchmarking to monitor impact of direct acting antivirals. J Viral Hepat. 2018;25:482-90. https://doi.org/10.1111/jvh.12844.

10 European Monitoring Centre for Drugs and Drug Addiction. Hepatitis C among drug users in Europe: epidemiology, treatment and prevention, EMCDDA insights 23. Luxembourg: Publications Office of the EU; 2016.

11 Grebely J, Bruneau J, Bruggmann P, Harris M, Hickman M, Rhodes T, Treloar C. Elimination of hepatitis C virus infection among PWID: the beginning of a new era of interferon-free DAA therapy. Int J Drug Policy. 2017;47:26-33. https://doi.org/10.1016/..drugpo.2017.08.001.

12 Wade AJ, Veronese V, Hellard ME, Doyle JS. A systematic review of community based hepatitis C treatment. BMC Infect Dis. 2016;16:202. https://doi.org/10.1186/s12879-016-1548-5.

13 Falade-Nwulia O, Suarez-Cuervo C, Nelson DR, Fried MW, Segal JD, Sulkowski MS. Oral direct-acting agent therapy for hepatitis $C$ virus infection: a systematic review. Ann Intern Med. 2017;166:637-48. https://doi.org/10.7326/M16-2575.

14 Guidelines for the care and treatment of persons diagnosed with chronic hepatitis C virus infection. Geneva: World Health Organization; 2018. https:/apps. who.int/iris/bitstream/handle/10665/273174/9789241550345-eng.pdf?ua=1

15 Liberati A, Altman DG, Tetzlaff J, Mulrow C, Gøtzsche PC, loannidis JPA, Clarke M, Devereaux J, Kleijnen J, Moher D. The PRISMA statement for reporting systematic reviews and meta-analyses of studies that evaluate healthcare interventions: explanation and elaboration. Br Med J. 2009;339: b2700. https://doi.org/10.1136/bmj.b2700.

16 Emmanuel B, Wilson EM, O'Brien TR, Kottilil S, Lau G. Shortening the duration of therapy for chronic hepatitis $C$ infection. Lancet Gastroenterol Hepatol. 2017;2(11):832-6. https://doi.org/10.1016/S2468-1253(17)30053-5.

17 World Health Organisation. Main terminology - primary health care. http:// www.euro.who.int/en/health-topics/Health-systems/primary-health-care/ main-terminology ().

18 Higgins JPT, Green S (editors). Cochrane Handbook for Systematic Reviews of Interventions Version 5.1.0 [updated March 2011]. The Cochrane Collaboration, 2011. Available from http://handbook.cochrane.org. ().

19 Wells GA, Shea B, O'Connell D, Peterson J, Welch V, Losos M, Tugwell P. The Newcastle-Ottawa Scale (NOS) for assessing the quality of nonrandomised studies in meta-analyses http://www.ohri.ca/programs/_linical_ epidemiology/oxford.asp ().

20 Sabbagh HJ, Hassan M, Hassan A, Innes NP, Elkday HM, Little J, Massey PA. Passive smoking in the etiology of non-Syndromic Orofacial clefts: a systematic review and meta-analysis. PLoS One. 2015. https://doi.org/10. 1371/journal.pone.0116963.

21 Berkman ND, Lohr KN, Ansari MT, Balk EM, Kane R, McDonagh M, Morton SC, Viswanathan M, Bass EB, Butler M, Gartlehener G, Hartley L, McPheteers M, Morgan LC, Reston J, Sista P, Whitlock E, Chang S. Grading the strength of a body of evidence when assessing health care interventions: an EPC update. J Clin Epidemiol. 2015;68:1312e1324.

22 Bloom S, Lubel J, Nicoll A, Gow P, Dev A, Roberts S, Bell S, Kronberg I, Knight V, Sood S, Lewis D, Kemp W, On behalf of the Melbourne Liver Group. Comparison of direct-acting antiviral therapy for hepatitis $C$ between specialist centres and primary care: efficacy and adherence to response assessment. J Gastroenterol Hepatol. 2017;32, 65(suppl 2). https://doi.org/10.1111/jgh.13892.

23 Francheville JW, Rankin R, Beck J, Hoare C, Materniak S, German G, Barrett L, Bunimov-Wall N, Smyth D. Early success in an open access provincially funded hepatitis $C$ treatment program in Prince Edward Island. Ann Hepatol. 2017;16(5):749-58. https://doi.org/10.5604/01.3001.0010.2757.

24 Kattakuzhy S, Gross C, Emmanuel B, Teferi G, Jenkins V, Silk R, Akoth E, Thomas A, Ahmed C, Espinosa M, Price A, Rosenthal E, Tang L, Wilson E, Bentzen S, Masur H, Kottilil S, the ASCEND Providers. Expansion of treatment for hepatitis $C$ virus infection by task shifting to community-based nonspecialist providers: a nonrandomized clinical trial. Ann Inter Med. 2017;167: 311-8. https://doi.org/10.7326/M17-0118.

25 McClure T, Olenski M, Ward A, Glasgow S, Stothers L, New K, Papaluca T, Wong D, Burns G, Valaydon Z, Mei SCY, Jeremiah C, Visvanathan K, Croagh C, Howell J, Hong T, Ryan M, Demeduik B, Lust M, Shaw G, Iser D, Nguyen T, Desmond $\mathrm{P}$, Bell $\mathrm{S}$, Thompson AJ. Real-world treatment for hepatitis $\mathrm{C}$ in the direct acting antiviral era: Comparing outcomes between the tertiary liver clinic and community J Gastroenterol Hepatol 2017; 32: (suppl 2): 74. DOl:https://doi.org/10.1111/jgh.13892

26 Miller L, Quairoli K, Lom J, Fluker SA. Access to and success with new hepatitis $\mathrm{c}$ therapy in an urban primary care centre. J. General Internal Medicine 2016: 31 (2) 1: S110. 10.1007\%2Fs11606-016-3657-7

27 Norton BL, Fleming J, Bachhuber MA, Steinman M, DeLuca J, Cunningham CO, Johnson N, Laraque F, Litwin AH. High HCV cure rates for people who use drugs treated with direct acting antiviral therapy at an urban primary care clinic. Int J Drug Policy. 2017:47:196-201 https://doi.org/10.1016/j. drugpo.2017.07.021.

28 Wade AJ, Doyle JS, Gane E, Stedman C, Draper B, Iser D, Roberts SK, Kemp W, Petrie D, Scott N, Higgs P, Agius PA, Roney J, Stothers L, Thompson AJ, Hellard ME. Outcomes of Treatment for Hepatitis C in Primary Care, Compared to Hospital-based Care: A Randomized, Controlled Trial in People Who Inject Drugs. Clin Infect Dis. 2019:ciz546. https://doi.org/10.1093/cid/ciz546.

29 Abdulameer A, Leff P, Joshi K, Hepner A, Moore A, Arendt K, Reynolds J, Gish R, Manch R, Kohli A. Effectiveness of sofosbuvir/ledipasvir and sofosbuvir/ simeprevir for the treatment of hepatitis C genotype-1: Real world analysis. Hepatology 2016; 64 (1) S1: 989A-990A.

30 Beste LA, Glorioso TJ, Ho PM, Au DH, Kirsch SR, Todd-Stenberg J, Chang MF, Dominitz JA, Baron AE. Telemedicine speciality support promoites hepatitis $C$ treatment by primary care providers in the department of vetrerans affairs. Am J Med. 2017;130(4):432-8. https://doi.org/10.1016/j.ammed.2016.11.019.

31 Buchanan R, Shalabi A, Parkes J, Khakoo S. Hepatology outreach services to overcome inequalities in hepatitis $\mathrm{C}$ care in an isolated UK population (PTU 112). Gut. 2015;64(supp|1):A1-A584.

32 Georgie F, Nafisi S, Kohli A, Thornton K, Reynolds J, Moore A, Gish R, Scott J, Deming P, Sedillo M, Qualls C, Box T, Cox P, Mera J, Miller A, Sussman N, Khaderi S, Manch R, Arora S. Primary care physicians utilising the ECHO model equally effective as subspecialists treating HCV using direct-acting antivirals-only regimens: results of the ECHO model (SAT-260). J Hepatol. 2016;64:S631-832. https://doi.org/10.1016/50168-8278(16)01600-7.

33 Butner JL, Gupta N, Fabian C, Henry S, Shi JM, Tetrault JM. Onsite treatment of HCV infection with direct acting antivirals within an opioid treatment program. J Subst Abus Treat. 2017;75:49-53. https:/doi.org/10.1016/j.sat.2016.12.014.

34 Morris L, Smirnov A, Kvassay A, Leslie E, Kavanagh R, Alexander N, Davey G, Williams O, Gilks C, Najman J. Initial outcomes of integrated communitybased hepatitis $\mathrm{c}$ treatment for people who inject drugs: findings from the Queensland injectors' health network. Int J Drug Policy. 2017:47:216-20. https://doi.org/10.1016/j.drugpo.2017.05.056. 
35 Read P, Lothian R, Chronister K, Gilliver R, Kearley J, Dore GJ, van Beck I. Delivering direct acting antiviral therapy for hepatitis $\mathrm{C}$ to highly marginalised and current drug injecting populations in atargeted primary health care setting. Int J Drug Policy. 2017:47:209-15. https://doi.org/10. 1016/j.drugpo.2017.05.032.

36 David C, David D, Essex W, Deming P, Qualls CR, Mera J. Hepatitis C treatment outcomes in a pharmacist-managed clinic in a rural tribal health system. Hepatology 2017; 66 (s1): 331A. Poster 609.

37 Radley A, Tait J, Dillon JF. DOT-C: a cluster randomised feasibility trial evaluating directly observed anti-HCV therapy in a population receiving opioid substitution therapy from a community pharmacy. Int J Drug Policy. 2017;47:126-36. https://doi.org/10.1016/j.drugpo.2017.05.042.

38 Cooper CL, Hatashita H, Corsi DJ, Parmar P, Corrin R, Garber G. Direct-acting antiviral therapy outcomes in Canadian chronic hepatitis c telemedicine patients. Ann Hepatol. 2017:16(6):874-80. https://doi.org/10.5604/01.3001.0010.5277.

39 Ní Cheallaigh C, O'Leary A, Keating S, Singleton A, Heffernan S, Keenan E, Robson L, Sears J, Moloney J, Arora S, Bergin C, Norris S On behalf of the Irish Hepatitis C Outcomes Research Network. Telementoring with project ECHO: a pilot study in Europe. BMJ Innovations 2017;3:144-151. doi:https:// doi.org/10.1136/bmjinnov-2016-000141.

40 Shehata N, Austin T, Ha S, Timmerman K. Barriers and facilitators of hepatitis $C$ virus screening and testing: a scoping review Canadian Communicable Diseases Reports 2018; 44:7-8. PMID:31011297

41 Aspinall EJ, Doyle JS, Corson S, Hellard ME, Hunt D, Goldberg D, Nguyen T, Ytter YF, Morgan RL, Smith B, Stoove M, Wiktor SZ, Hutchinson S. Targeted hepatitis $C$ antibody testing interventions: a systematic review. Eur J Epidemiol. 2015;30:115-29. https://doi.org/10.1007/s10654-014-9958-4.

42 McDermott CL; Lockhart CM, Devine B. Outpatient directly observed therapy for hepatitis $C$ among people who use drugs: a systematic review and meta-analysis. J Virus Eradication 2018; 4 (2): 118-122. PMC5892673.

43 Grebely J, Dore GJ, Morin S, Rockstroh JK, Klein MB. Elimination of HCV as a public health concern among people who inject drugs by 2030 - what will it take to get there? J Int AIDS Soc. 2017;20(1):22146. https://doi.org/10. 7448/IAS.20.1.22146.

44 Wade AJ, McCormack A, Roder C, McDonald K, Davies M, Scott N, Wardrop M, AThan E, Hellard ME. Aiming for elimination: outcomes of a consultation pathway supporting regional general practitioners to prescribe direct-acting antiviral therapy for hepatitis C. J Viral Hepat. 2018:1-10. https://doi.org/10. 1111/jvh.12910.

45Rackede Bruin M, Inglis SK, Donnan PT, Dillon JF. Clinical effectiveness of pharmacy-led versus conventionally delivered antiviral treatment for Hepatitis C in patients receiving opioid substitution therapy: A study protocol for "SuperDOT-C" -a pragmatic cluster randomised trial. BMJ Open 2018 DOI: https://doi.org/10.1136/bmjopen-2017-021443

46. Swan D, Cullen W, Macias J, Oprea C, Story A, Surey J, Vickerman P S. Lambert JS. Hepcare Europe - bridging the gap in the treatment of hepatitis C: study protocol, Expert Review of Gastroenterology \& Hepatology 2018, 12:3, 303-314, DOl: https://doi.org/10.1080/17474124. 2018.1424541

47. Martin NK, Vickerman P, Grebely J, et al. Hepatitis C virus treatment for prevention among people who inject drugs: modeling treatment scale-up in the age of direct-acting antivirals. Hepatology. 2013:58:1598-609. https:// doi.org/10.1002/hep.26431.

\section{Publisher's Note}

Springer Nature remains neutral with regard to jurisdictional claims in published maps and institutional affiliations.

Ready to submit your research? Choose BMC and benefit from:
- fast, convenient online submission
- thorough peer review by experienced researchers in your field
- rapid publication on acceptance
- support for research data, including large and complex data types
- gold Open Access which fosters wider collaboration and increased citations
- maximum visibility for your research: over 100M website views per year
At BMC, research is always in progress.
Learn more biomedcentral.com/submissions

